\title{
WEIGHT REDUCTION IN BRAKE DISC USING TOPOLOGY OPTIMIZATION
}

\author{
Swapnil Thigale ${ }^{1}$, Chinmay Shah ${ }^{2}$ \\ ${ }^{1}$ Student, Department of Mechanical, Vishwakarma Institute of Technology, Maharashtra, India \\ ${ }^{2}$ Student, Department of Mechanical, Vishwakarma Institute of Technology, Maharashtra, India
}

\begin{abstract}
Abstract -To design a lighter brake disc than the existing models used in general two wheelers is the main objective of this paper. The newly optimized brake disc is compared with existing BAJAJ Discover125M disc. Topology optimization for weight reduction was performed by using Altair INSPIRE 9.5 software and the newly optimized disc was analyzed in ANSYS16.0.Using this method a new light-weight brake disc is designed. The results of the design shows that the weight of a new brake disc is $26.68 \%$ less as compared to the existing brake disc and it has similar performance as the existing disc.
\end{abstract}

Keywords: Weight Reduction, Topology optimization, INSPIRE and brake disc.

\section{INTRODUCTION}

The braking system converts the kinetic energy of the moving vehicle into heat. Disc brakes are a type of brakes that uses discs (as opposed to rims or drums) as the braking surface. This type of brake is used on many types of vehicles such as cars, motorcycles, and bicycles. In bikes the discs which are currently in use are plain discs without much optimization done on them. Their weight can be certainly reduced by employing weight reduction through topology optimization without negotiating with the required strength. The main components of a disc brake system are the brake caliper, which houses pistons and brake pads, and the rotor. A typical configuration of disc brake caliper and rotor can be seen in the cross sectional view shown in Figure1. Pistons are usually actuated hydraulically or mechanically.

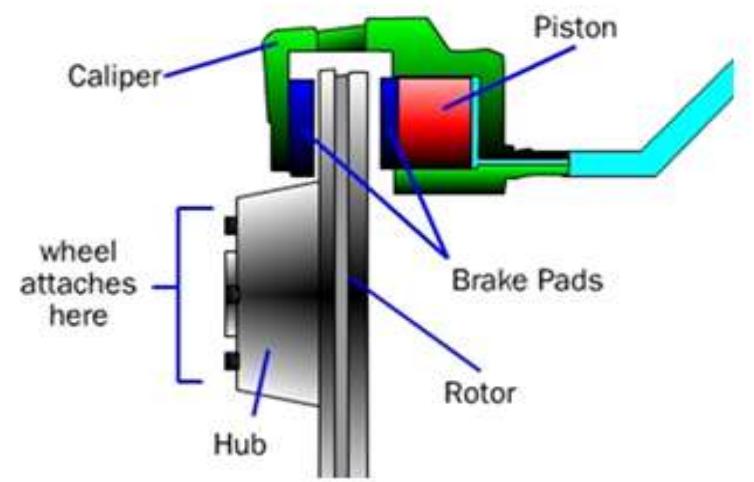

Fig-1: Brake disc system

By reducing the weight of the vehicle we can improve the fuel consumption. When the mass of vehicle is reduced the inertialforces which has to be overcome by engine also reduces, and the energy required for vehicle to move is also less. Generally for every $10 \%$ reduction in weight of the vehicle, the fuel consumption of vehicles is reduced by 5 $7 \%$ [1].The reduction in mass of a brake disc is a small percentage of the total mass, but it is a collection of components that make up the total mass of the vehicle. The total weight of the vehicle weight has significant impact on performance. Overall, a light vehicle should perform better since the engine capacity is fixed. While reducing the mass of the rotor alone may seem insignificant, doing so along with mass reductions of all other possible components can be significant.

\section{LITERATURE SURVEY}

Topology optimization uses a mathematical approach to optimize material layout and it is done within a given design space. It uses appropriate boundary conditions for given particular application and solves the mathematical model and finally it gives an optimized design which satisfies the requirements of the designer. This method of optimizing the existing geometries without sacrificing performance requirements has many applications. Cavazzuti et al. [2] used this method and designed the chassis of an automobile. Kaya et al. [3] with the help of this technique redesigned a clutch fork. Response surface methodology was adopted for designing the clutch fork. Topology optimization has provided engineers a tool that helps them to develop the best design meeting every aspect of performance. Finite element analysis is used for analysis to implement the generated topologies.[4]Topology optimization technique is applied initially at the concept level to get an initial design which then further optimized considering its performance as well as manufacturing aspect. This helps to save the time of costly and time consuming design iterations and hence reducing the overall cost. Sometimes the designs generated by topology optimization are in accordance to performance but difficult to manufacture and hence necessary design changes are made during the design process considering the manufacturing aspect. 


\section{APLLICATION OF TOPLOGY OPTIMIZATION IN BRAKE DISC}

Brake Disc is generally designed by iterative methods and it is optimized under topologies which are not well optimized. They are often based on static loading conditions. To obtain the optimal layout following steps were carried out.

\subsection{Beginning with the Non-Optimized Disc}

Firstly a CAD model of the disc was prepared on SOLIDWORKS16.0.Figure3 shows the initial model. The overall dimensionsions and the mounting positions were created.

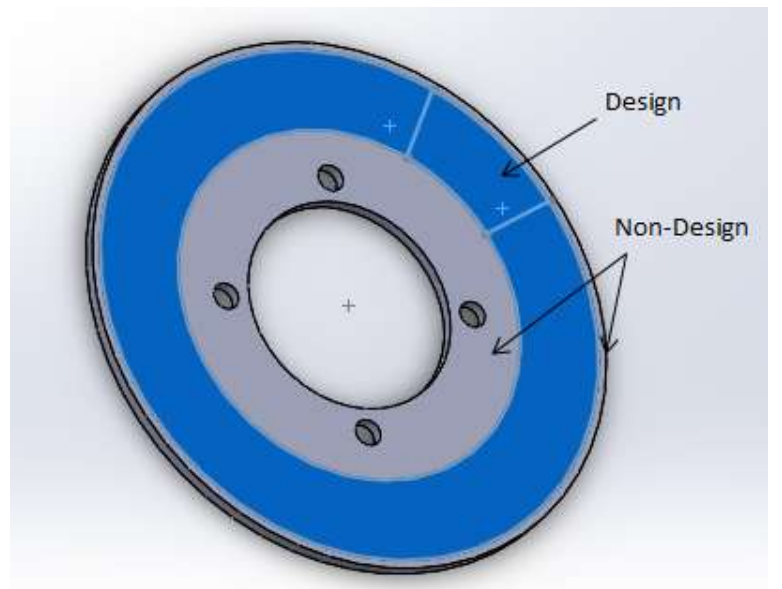

Fig-2: CAD model in solid works 16.0

The disc was divided into two main regions, The Design and Non-Design space.

\subsection{Calculation of Forces}

The following parameters are considered [5].

Table-1: Brake System Parameters

\begin{tabular}{|l|l|l|l|l|}
\hline $\begin{array}{l}\text { Sr. } \\
\text { no. }\end{array}$ & Parameters & symbol & Value & units \\
\hline 1. & Input driver force & $\mathrm{F}$ & 160 & $\mathrm{~N}$ \\
\hline 2. & Pedal ratio & $\mathrm{n}$ & 4 & - \\
\hline 3. & $\begin{array}{l}\text { Bore diameter of } \\
\text { master cylinder }\end{array}$ & $\mathrm{dm}$ & 0.013 & $\mathrm{~m}$ \\
\hline 4. & $\begin{array}{l}\text { Diameter of caliper } \\
\text { piston }\end{array}$ & $\mathrm{dc}$ & 0.0315 & $\mathrm{~m}$ \\
\hline 5. & $\begin{array}{l}\text { Disc-Pad } \\
\text { coefficient friction }\end{array}$ & $\mu$ & 0.4 & - \\
\hline 6. & $\begin{array}{l}\text { Area of master } \\
\text { cylinder }\end{array}$ & $\mathrm{A}$ & $1.326 \mathrm{e}^{\wedge}-4$ & $\mathrm{~m}^{\wedge} 2$ \\
\hline 5. & $\begin{array}{l}\text { Area of caliper } \\
\text { Effective radius of }\end{array}$ & $\mathrm{Re}$ & $7.7891 \mathrm{e}^{\wedge}-4$ & $\mathrm{~m}^{\wedge} 2$ \\
\hline 6. & $\begin{array}{l}\text { Effer } \\
\text { disc }\end{array}$ & $\mathrm{m}$ \\
\hline
\end{tabular}

\section{Calculations}

1. Force at master cylinder $(\mathrm{Fm})=\mathrm{F} \times \mathrm{n}=640 \mathrm{~N}$

2. Pressure $(\mathrm{P})=\mathrm{Fm} / \mathrm{A}=4824181.2083 \mathrm{~Pa}$
3. Force at caliper $(\mathrm{Fn})=\mathrm{P} / \mathrm{a}=3757.63 \mathrm{~N}$

4. Total Clamping force $(\mathrm{Fc})=2 \times \mu \times \mathrm{Fn}=3006.1 \mathrm{~N}$

5. Clamping force on each side $=1503.053 \mathrm{~N}$

6. Braking Torque $(\mathrm{T})=\mathrm{Fc} \times \mathrm{Re}=255.51 \mathrm{Nm}$

\subsection{Loads and Constraints}

The brake disc is mounted to hub of wheel by five M6 bolts. The bolts are considered to be fully tight and rotor is fully constrained to wheel. Cyclic symmetry was applied to the system and clamping force of $3006.1 \mathrm{~N}$ was applied at pad section. The pad section area is of the size of actual brake pad of the caliper used in BAJAJ Discover bike. The disc was divided into total 12 sectors. The dark region is the design space and light coloured region in Non-design space. The red arrows shows the direction of applied force and the red circles shows the fixed cylindrical support.

Material of disc: SS430 [6].

Maximum ultimate tensile strength: $517 \mathrm{MPa}$

Maximum yield strength: $345 \mathrm{MPa}$

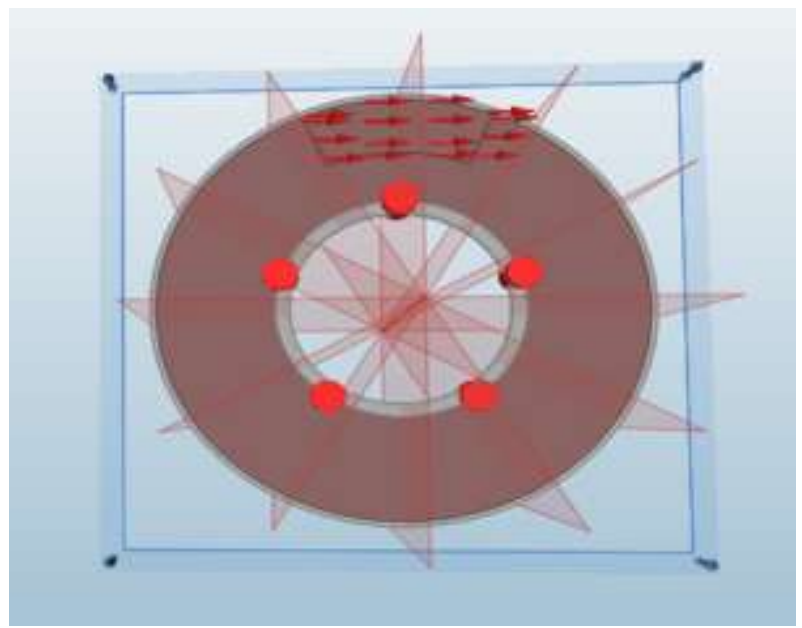

Fig-3: Sectors and constraints in INSPIRE 9.5

Finally optimization was run on INSPIRE 9.5 for maximum stiffness and minimum mass criteria.

The results obtained were as follows:

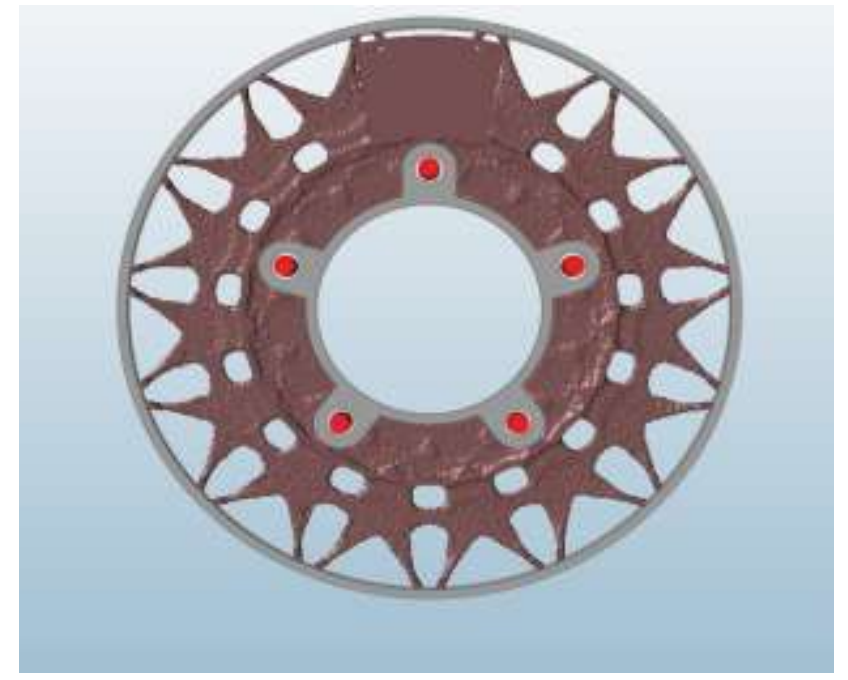

Fig-4: Result obtained from INSPIRE 9.5 
The results obtained shows that where the material reduction can be done. The software INSPIRE 9.5 gives the idea about the initial design with help of which actual design is created. Considering the obtained results the CAD model of disc was made on Solidworks 16.0. Weight reduction slots were made at appropriated locations and necessary thickness of disc which is required was given.

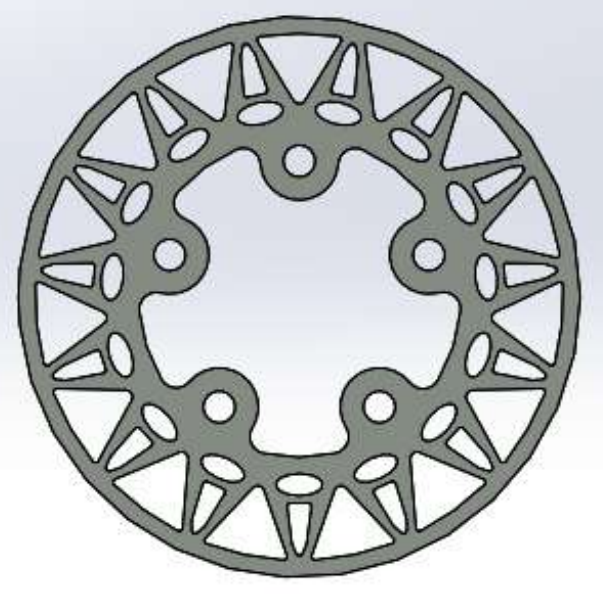

Fig-5: Final Design after Topology Optimization created in SOLIDWORKS 16.0

\subsection{Validation}

To validate the current prepared model, a finite element analysis was done to make sure that the design is within safety limits. The analysis was carried on ANSYS 16.0. A clamping force of $1503.053 \mathrm{~N}$ was applied on both sides of pad region tangential to the direction on rotation. The disc was given fixed support at the mounting points.

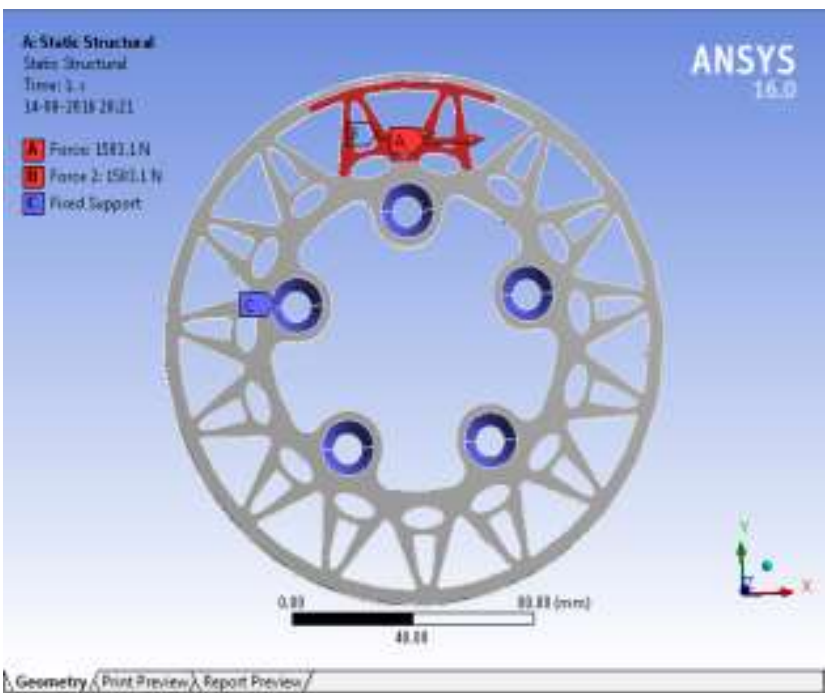

Fig-6: Loads and constraints applied in ANSYS16.0

The material of the disc is assumed to be homogenous and isotropic. The domain of the problem is assumed as axissymmetric. During the analysis of disc inertia $\&$ body force effects are very small and hence neglected.

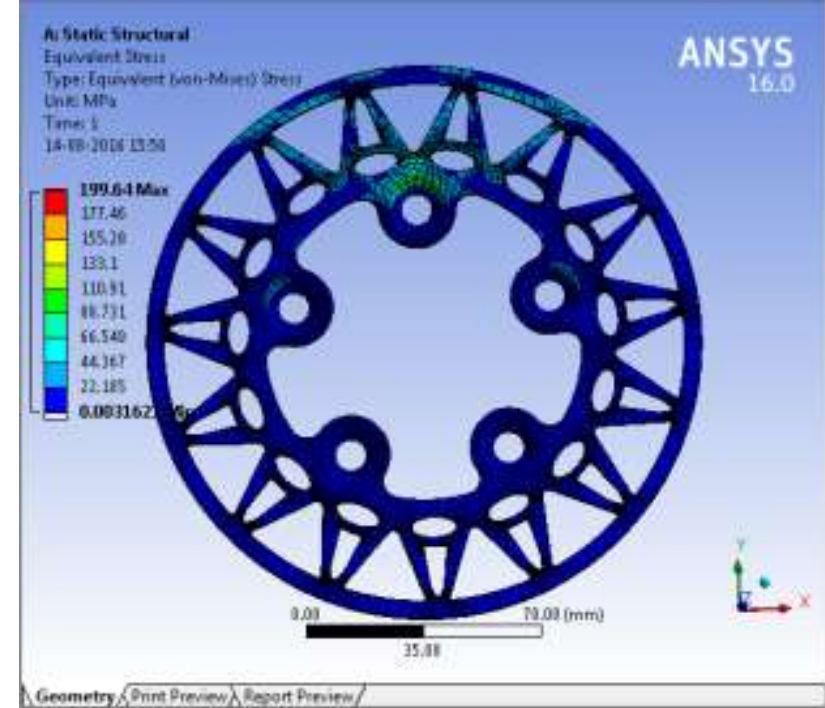

Fig-7: Equivalent stress

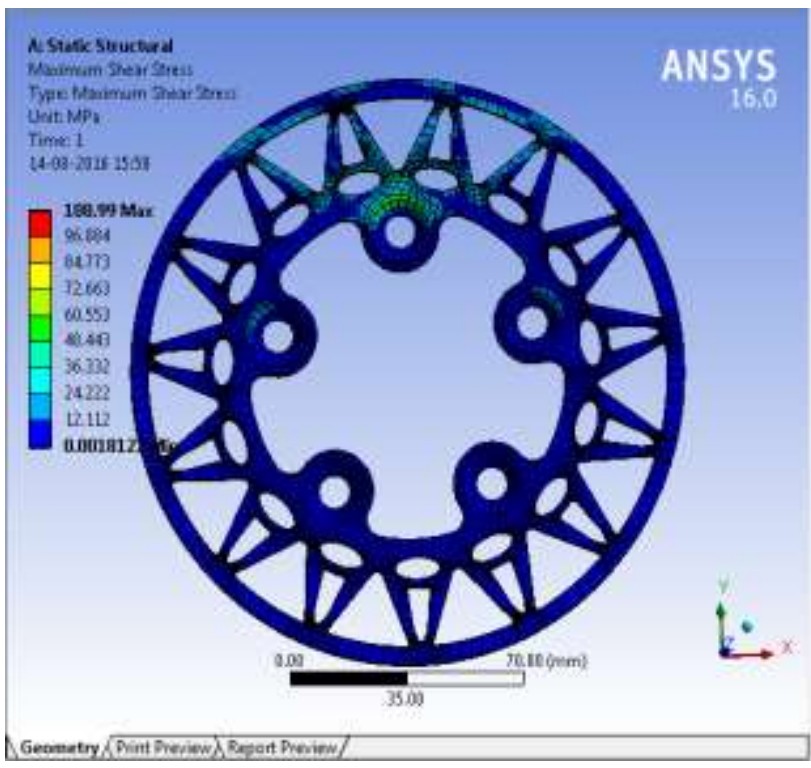

Fig-8: Maximum Shear Stress

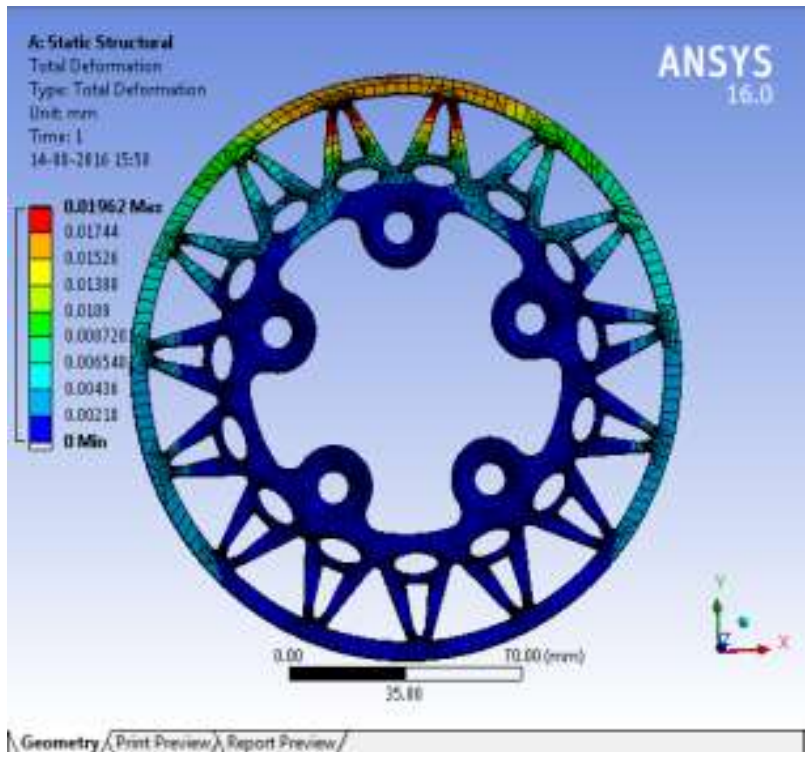

Fig-9: Total Deformation 
Using maximum shear stress theory [7] the yield strength in shear is half of the yield stress in tension.

Ssy $=0.5$ Syt

Factor of safety $=$ Ssy/shear stress in disc

\subsection{Comparison with Previous Disc}
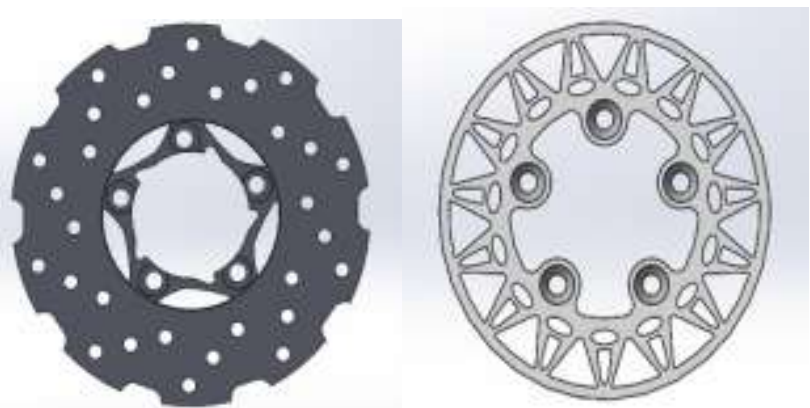

Optimized Disc

BAJAJ Discover 125M

\section{BIOGRAPHIES}

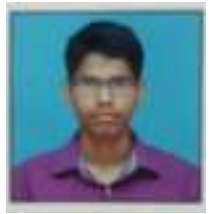

Swapnil Balkrishna Thigale, Student at Mechanical Department, Vishwakarma Institute of Technology, Pune. Member of Engine and Transmission of BAJA SAE team ENDURANCE RACING.

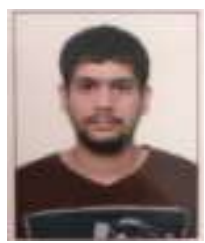

Chinmay Shah, Student at Mechanical Department, Vishwakarma Institute of Technology, Pune. Member of Engine and Transmission of BAJA SAE team ENDURANCE RACING.

Table-2: Comparison

\begin{tabular}{|l|l|l|}
\hline & $\begin{array}{l}\text { BAJAJ } \\
\text { Discover } \\
125 \mathrm{M} \text { disc }\end{array}$ & $\begin{array}{l}\text { New optimized } \\
\text { disc }\end{array}$ \\
\hline Weight & $539.39 \mathrm{~g}$ & $395.45 \mathrm{~g}$ \\
\hline Maximum Deflection & $0.0174 \mathrm{~mm}$ & $0.0196 \mathrm{~mm}$ \\
\hline Max shear stress & $106.48 \mathrm{Mpa}$ & $108.99 \mathrm{Mpa}$ \\
\hline Factor of safety & 1.62 & 1.5827 \\
\hline
\end{tabular}

\section{CONCLUSION}

Topology optimization was performed on disc by determining the constraints in the design and appropriate boundary conditions to reduce its weight. The new disc is $26.68 \%$ lighter than the previous disc.By using this knowledge of topology optimization with engineering aspect an optimized brake disc design can be made in short time.

\section{REFRENCES}

[1] Ashley, S. (2010) Shedding pounds on a magnesium diet. Automotive Engineering International, pp. 3436.

[2] Cavazzuti, M., Baldini, A., Bertocchi, E., Costi, D., Torricelli, E., \& Moruzzi, P. (2011a). High performance automotive chassis design: a topology optimization based approach. Structural and Multidisciplinary Optimization, Vol.44 (1), pp4556.B.

[3] Kaya, N., Karen, İ., \& Öztürk, F. (2010). Re-design of a failed clutch fork using topology and shape optimization by the response surface method. Materials \& Design, 31(6), 3008-3014.

[4] Bendsøe, M.P. and Sigmund, O. (2003) Topology Optimization - Theory, Methods and Applications. Springer Verlag, Berlin Heidelberg.

[5] The Physics of Braking Systems By James Walker, (2005), Stoptech LLC.

[6] htttp://asm.matweb/search/SpecificMaterial.asp?bass num=MQ430.AN material datasheet.

[7] V B Bhandari (1994),Design of Machine Elements, Third Edition, Pg 108. 